\title{
Stereotactic body radiation therapy for the treatment of localized prostate cancer in men with underlying inflammatory bowel disease
}

\author{
Jonathan W. Lischalk ${ }^{1 *}$, Seth Blacksburg², Christopher Mendez ${ }^{1}$, Michael Repka ${ }^{1}$, Astrid Sanchez ${ }^{1}$, \\ Todd Carpenter ${ }^{1}$, Matthew Witten ${ }^{1}$, Jules E. Garbus ${ }^{3}$, Andrew Evans ${ }^{4}$, Sean P. Collins ${ }^{5}$, Aaron Katz ${ }^{6}$ and \\ Jonathan Haas ${ }^{1}$
}

American Society for Radiation Oncology Annual Conference poster presentation October 21st to 24th, 2018, San Antonio, TX.

\begin{abstract}
Background: Historically, IBD has been thought to increase the underlying risk of radiation related toxicity in the treatment of prostate cancer. In the modern era, contemporary radiation planning and delivery may mitigate radiation-related toxicity in this theoretically high-risk cohort. This is the first manuscript to report clinical outcomes for men diagnosed with prostate cancer and underlying IBD curatively treated with stereotactic body radiation therapy (SBRT).

Methods: A large institutional database of patients $(n=4245)$ treated with SBRT for adenocarcinoma of the prostate was interrogated to identify patients who were diagnosed with underlying IBD prior to treatment. All patients were treated with SBRT over five treatment fractions using a robotic radiosurgical platform and fiducial tracking. Baseline IBD characteristics including IBD subtype, pre-SBRT IBD medications, and EPIC bowel questionnaires were reviewed for the IBD cohort. Acute and late toxicity was evaluated using the CTCAE version 5.0.

Results: A total of 31 patients were identified who had underlying IBD prior to SBRT for the curative treatment of prostate cancer. The majority $(n=18)$ were diagnosed with ulcerative colitis and were being treated with local steroid suppositories for IBD. No biochemical relapses were observed in the IBD cohort with early follow up. High-grade acute and late toxicities were rare ( $n=1$, grade 3 proctitis) with a median time to any $\mathrm{Gl}$ toxicity of 22 months. Hemorrhoidal flare was the most common low-grade toxicity observed $(n=3)$.
\end{abstract}

Conclusion: To date, this is one of the largest groups of patients with IBD treated safely and effectively with radiation for prostate cancer and the only review of patients treated with SBRT. Caution is warranted when delivering

\footnotetext{
*Correspondence: jonathan.lischalk@nyulangone.org

${ }^{1}$ Department of Radiation Oncology, NYCyberKnife at Perlmutter Cancer

Center - Manhattan, Perlmutter Cancer Center at New York University

Langone Hospital - Long Island, 150 Amsterdam Ave, New York, NY

11501, USA

Full list of author information is available at the end of the article
}

(c) The Author(s) 2021. Open Access This article is licensed under a Creative Commons Attribution 4.0 International License, which permits use, sharing, adaptation, distribution and reproduction in any medium or format, as long as you give appropriate credit to the original author(s) and the source, provide a link to the Creative Commons licence, and indicate if changes were made. The images or other third party material in this article are included in the article's Creative Commons licence, unless indicated otherwise in a credit line to the material. If material is not included in the article's Creative Commons licence and your intended use is not permitted by statutory regulation or exceeds the permitted use, you will need to obtain permission directly from the copyright holder. To view a copy of this licence, visit http://creativecommons.org/licenses/by/4.0/. The Creative Commons Public Domain Dedication waiver (http://creativeco mmons.org/publicdomain/zero/1.0/) applies to the data made available in this article, unless otherwise stated in a credit line to the data. 
therapeutic radiation to patients with IBD, however modern radiation techniques appear to have mitigated the risk of Gl side effects.

Keywords: Prostate, Stereotactic body radiation therapy, Inflammatory bowel disease, Ulcerative colitis, Crohn's disease

\section{Background}

Inflammatory bowel disease (IBD) is a chronic idiopathic inflammatory disorder that affects over one million individuals in the United States and is increasing in incidence $[1,2]$. The illness is separated into two distinct subtypes: (1) Crohn's disease (CD), and (2) ulcerative colitis (UC). Each type carries discrete anatomical and pathophysiological characteristics, but both can fundamentally worsen baseline bowel function [3]. Moreover, IBD carries an increased risk of secondary malignancies [4]. As such, notable efforts have been made to minimize exposure of patients diagnosed with IBD to ionizing radiation even those used for diagnostic purposes [5-8].

Autoimmune disorders including IBD are thought to lead to synergistic increases in toxicity when combined with therapeutic radiation, and great caution has been historically exercised with their combination. A systemic review of the literature identified only eight trials with a total of 144 patients diagnosed with underlying IBD and treated with pelvic radiotherapy [9]. Small case studies have warned against the use of radiation in cases of underlying IBD, and have labeled therapeutic radiation as a "relative contraindication" $[10,11]$. Older data from Massachusetts General Hospital (MGH) reported nearly a $50 \%$ rate of "severe toxicity" in 28 patients identified from 1970 to 1999 who were treated with abdominopelvic radiotherapy for a variety of malignancies including seven patients with prostate cancer [12]. Such late toxicity included $29 \%$ of patients requiring surgical intervention or hospitalization. Therefore, in cases such as prostate cancer where definitive treatment options exist outside of radiation, such alternative local therapies have thus been prudently advocated [12]. It is important to note that anti-inflammatories used to manage IBD can also increase the risk of wound dehiscence and infection following surgery, thus their peri-operative discontinuation may in and of itself flair underlying IBD [13].

In the current era, the toxicity risk with radiation appears to be lower if patients are carefully selected and new radiation modalities are utilized [14-19]. Stereotactic body radiation therapy (SBRT) has been demonstrated to be clinically effective and has become a ubiquitous option for selected men with localized adenocarcinoma of the prostate [20]. However, no literature exists regarding the acute and late toxicity for men with underlying IBD treated with SBRT for prostate cancer. It is reasonable to hypothesize that SBRT using contemporary imaging, advanced treatment planning, and precise radiation delivery could mitigate radiation-related toxicity in this theoretically higher risk cohort.

In this manuscript, we describe our large institutional experience, spanning nearly a decade, and review the clinical outcomes of patients diagnosed with underlying IBD and subsequently treated with SBRT for localized prostate cancer.

\section{Methods}

\section{Patient eligibility}

This single institutional review of patients treated with SBRT for prostate cancer was approved by the local Institutional Review Board (Study \# 00001269). All patients were evaluated by a radiation oncologist and deemed appropriate for definitive SBRT. All patients underwent pre-treatment diagnostic tests including clinical examination, PSA, and transrectal ultrasound-guided biopsy. Patients were categorized into D'Amico risk group classifications. All patients underwent placement of fiducial markers in the prostate approximately one week prior to simulation. Fiducial markers were utilized for inter- and intra-fractional image guidance using a robotic radiosurgical platform. Patient IBD history was reviewed in detail to determine the diagnosed subtype of disease as UC, CD, or IBD not otherwise specified. Pre-SBRT IBD treatment (e.g. suppositories, systemic steroids, etc.) was reviewed and documented (Table 2).

\section{Simulation, planning, and treatment delivery}

All patients underwent computed tomography (CT)based radiation treatment planning simulation (GE Optima 580). An MRI of the prostate was also obtained in the majority of cases at the time of simulation and fused with the primary simulation CT scan at the level of the fiducials to assist in target volume delineation with particular attention paid to the prostate and rectal interface. Patients were recommended enema usage prior to simulation and delivery of each treatment fraction. Target volume contours were generated using previously defined definitions. Nodal radiation was incorporated for those patients deemed to be at high risk for nodal involvement. Organs at risk (OAR) were contoured and included rectosigmoid, bladder, penile bulb, small bowel, and femoral heads. 
Clinical target volume included the entire prostate and proximal seminal vesicles. A $5 \mathrm{~mm}$ isometric expansion of the CTV was created with a tighter, $3 \mathrm{~mm}$, posterior margin to form the PTV. Dose calculations and planning optimization were performed using Accuray MultiPlan software. Beam angles were created to optimize target volume coverage and minimize exposure of normal structures, with particular attention paid to the rectum. Dosimetric constraints for the aforementioned normal structures were utilized based on institutional standards. All patients were treated using SBRT delivered over five treatment fractions. Treatments were delivered using a robotic radiosurgical platform with prostate motion accounted for in the $\mathrm{x}-, \mathrm{y}-$, and $\mathrm{z}$-plane. All patients received intra-rectal amifostine in effort to reduce the risk of radiation-related GI toxicity. Finally, a small number of patients underwent pre-treatment rectal spacer placement, though the majority of patients were treated in an era prior to widespread spacer use.

\section{Follow-up}

Acute toxicity was defined as that occurring within 90 days of treatment completion. Late toxicity was defined as that occurring greater than 90 days after radiotherapy completion. Toxicity was reported using the Common Terminology Criteria for Adverse Events (CTCAE) version 5.0. Patients were followed using serial PSA and clinical examination commonly at 3-month intervals for the first year and subsequently every 6-12 months thereafter. Toxicity was measured from completion of SBRT. Patients who underwent EPIC questionnaires pre and post SBRT were reviewed with a specific focus on bowel habits.

\section{Statistical analysis}

Statistical analysis was performed using the Statistical Package for Social Sciences (SPSS) version 24 (Armonk, NY). The IBD and non-IBD cohort demographic, cancer, and treatment data were compared using Chi-Square analysis.

\section{Results}

\section{Patient and tumor characteristics}

In this single institutional retrospective review, we identified 4,245 patients who were treated with definitive SBRT for localized prostate cancer from 2012 to 2020. Of this cohort, 31 patients (1\%) were found to have an underlying diagnosis of IBD prior to undergoing SBRT. The majority of patients in the IBD cohort were between the ages of 60 and 70 years, and there was no significant difference $(p=0.58)$ in the age distribution between the IBD and non-IBD patients when analyzed as a continuous variable. The majority of IBD patients had an excellent documented ECOG performance status of 1 $(\mathrm{n}=18,58 \%)$. Androgen deprivation therapy was utilized as a component of treatment in the minority of patients $(\mathrm{n}=7,23 \%)$, and was not significantly different relative to the non-IBD cohort.

Within the IBD cohort, the prostate cancer risk grouping was as follows: low $(\mathrm{n}=8,26 \%)$, intermediate $(\mathrm{n}=17,55 \%)$, and high $(\mathrm{n}=6,19 \%)$. Pre-treatment PSA was $<10 \mathrm{ng} / \mathrm{mL}$ in the majority of patients $(\mathrm{n}=24,77 \%)$. There were no patients found to have locally advanced (i.e. clinical stage T3-4) disease and nearly half were diagnosed with pathologic grade group 2 cancer $(n=13$, $42 \%)$. There was no statistically significant difference identified between the IBD and non-IBD cohorts from a PSA $(p=0.09)$, clinical stage $(p=0.65)$, pathological grade group $(p=0.83)$, or overall risk group standpoint $(p=0.97)$. Patient and tumor characteristics are listed in Table 1.

\section{Inflammatory bowel disease diagnosis and severity prior to treatment}

Inflammatory bowel disease subtype was most commonly $\mathrm{UC}(\mathrm{n}=18,58 \%)$ followed by $\mathrm{CD}(\mathrm{n}=11,26 \%)$ with the remainder of patients having IBD not otherwise specified $(n=2,16 \%)$. The majority of patients $(n=24,77 \%)$ with IBD received medical treatment prior to undergoing radiotherapy. The majority of patients received treatment with local steroidal suppositories $(n=15,48 \%)$. However, systemic treatment was prescribed in nine patients (29\%) and included prednisone, hydroxychloroquine, and methotrexate amongst other medications. Anticoagulation use was not common in the IBD cohort $(n=5,16 \%)$. Nearly half of patients $(n=14)$ within the IBD cohort completed EPIC questionnaires prior to SBRT, which were interrogated for HRQOL bowel domain summary and bowel subscales. Overall, pretreatment HRQOL bowel domain summary scores for the IBD cohort were good with a median score of 90.18 (range, 37.50-100.0). The median pre-SBRT domain-specific HRQOL subscales for bowel function and bother were 94.64 (range, 46.43-100.00) and 91.07 (range, 28.57-100.00), respectively. Inflammatory bowel disease and EPIC questionnaire data details are shown in Tables 2 and 3, respectively.

\section{Treatment and dosimetric characteristics}

All patients were treated with SBRT to the prostate and proximal seminal vesicles. However, two patients within the IBD group received supplemental pelvic nodal irradiation followed by a prostate and seminal vesicle SBRT boost due to their high-risk disease. The majority of patients were treated to a total dose of $3500 \mathrm{cGy}$ in five fractions $(n=26,84 \%)$. Of the remaining patients, three were treated to $3625 \mathrm{cGy}$ and two patients received 
Table 1 Patient tumor and characteristics

\begin{tabular}{|c|c|c|c|c|c|}
\hline & \multicolumn{2}{|c|}{ IBD } & \multicolumn{2}{|c|}{ No IBD } & \multirow[t]{2}{*}{$p$ value } \\
\hline & $\mathrm{n}$ & $\%$ & $\mathrm{n}$ & $\%$ & \\
\hline \multicolumn{6}{|l|}{ Age } \\
\hline$<60$ years & 4 & $13 \%$ & 860 & $20 \%$ & \multirow[t]{3}{*}{0.58} \\
\hline $60-70$ years & 15 & $48 \%$ & 1840 & $44 \%$ & \\
\hline$>70$ years & 12 & $39 \%$ & 1514 & $36 \%$ & \\
\hline \multicolumn{6}{|l|}{ ECOG } \\
\hline 0 & 18 & $58 \%$ & & & \\
\hline 1 & 2 & $7 \%$ & & & \\
\hline No score & 11 & $35 \%$ & & & \\
\hline \multicolumn{6}{|l|}{ PSA (mg/mL) } \\
\hline$<10$ & 24 & $77 \%$ & 3281 & $78 \%$ & \multirow[t]{3}{*}{0.09} \\
\hline $10-20$ & 3 & $10 \%$ & 725 & $17 \%$ & \\
\hline$>20$ & 4 & $13 \%$ & 208 & $5 \%$ & \\
\hline \multicolumn{6}{|c|}{ AJCC 8-edition stage } \\
\hline $\mathrm{T} 1$ & 24 & $77 \%$ & 3436 & $82 \%$ & \multirow[t]{3}{*}{0.65} \\
\hline $\mathrm{T} 2$ & 7 & $23 \%$ & 733 & $17 \%$ & \\
\hline Т3-Т4 & 0 & $0 \%$ & 45 & $1 \%$ & \\
\hline \multicolumn{6}{|l|}{ Grade group } \\
\hline 1 & 9 & $29 \%$ & 1314 & $31 \%$ & \multirow[t]{5}{*}{0.83} \\
\hline 2 & 13 & $42 \%$ & 1436 & $34 \%$ & \\
\hline 3 & 4 & $13 \%$ & 833 & $20 \%$ & \\
\hline 4 & 3 & $10 \%$ & 418 & $10 \%$ & \\
\hline 5 & 2 & $6 \%$ & 213 & $5 \%$ & \\
\hline \multicolumn{6}{|l|}{ Risk group } \\
\hline Low & 8 & $26 \%$ & 1066 & $25 \%$ & \multirow[t]{3}{*}{0.97} \\
\hline Intermediate & 17 & $55 \%$ & 2392 & $57 \%$ & \\
\hline High & 6 & $19 \%$ & 756 & $18 \%$ & \\
\hline \multicolumn{6}{|l|}{ ADT } \\
\hline Yes & 7 & $23 \%$ & 943 & $22 \%$ & \multirow[t]{2}{*}{0.98} \\
\hline No & 24 & $77 \%$ & 3271 & $78 \%$ & \\
\hline
\end{tabular}

Table 2 Inflammatory bowel disease details

\begin{tabular}{lcc}
\hline IBD subtype & $n$ & $\%$ \\
Ulcerative colitis & 18 & 58 \\
Crohn's disease & 11 & 36 \\
Not otherwise specified & 2 & 6 \\
Pre-SBRT IBD medication & & \\
Mesalamine & 11 & 36 \\
Sulphasalazine & 4 & 13 \\
Prednisone & 2 & 6 \\
Hydroxychloroquine & 1 & 3 \\
Other & 6 & 19 \\
None & 7 & 23 \\
Blood thinner use & & \\
Coumadin & 3 & 6 \\
Aspirin & 2 & \\
\hline
\end{tabular}

*Azathioprine, balsalazide, budesonide, methotrexate, solasodine a prostate and seminal vesicle boost (2100 cGy and 1950 cGy each in 3 fractions) after nodal irradiation to 4500 cGy in 25 fractions. Most frequently, treatments were delivered on a consecutive day schedule $(n=29$, $94 \%)$. Only two patients within the IBD group underwent pre-treatment polyethylene glycol gel spacer placement. The remaining patients were treated with amifostine as a rectal protectant.

Dosimetric analysis of the IBD cohort (sans pelvic lymph nodes) was performed with particular attention paid to rectal dosimetry for the majority of patients $(n=27)$. Target volume coverage in the IBD cohort was excellent with CTV and PTV prescription coverage of $100 \%$ and $97 \%$, respectively. Median prescription isodose line was $84 \%$ (range, $83-87.5 \%$ ). Median maximum point dose to the rectum was $3754 \mathrm{cGy}$ with a median rectal $\mathrm{V} 3600 \mathrm{cGy}$ of $0.29 \mathrm{cc}$. The remaining radiation treatment and dosimetric details are listed in Table 4.

\section{Oncologic and toxicity outcomes}

Overall, excellent short-term oncologic outcomes were observed regardless of prostate cancer risk group classification in those men diagnosed with underlying IBD. With a median follow up of 22 months, no patients within the IBD cohort were found to have a Phoenix definition biochemical failure. The median and mean PSA nadir for those with IBD was found to be $0.35 \mathrm{ng} / \mathrm{mL}$ and $0.76 \mathrm{ng} / \mathrm{mL}$, respectively.

Overall, high-grade acute and late gastrointestinal toxicity was extremely rare $(n=1)$. Median time to any GI toxicity following SBRT was 22-months. One patient developed grade 3 proctitis requiring hospital management less than 1 month following SBRT. Two additional patients developed grade 2 proctitis requiring outpatient medical management at 22- and 29-months. Hemorrhoids, including hemorrhoidal hemorrhage, were the remaining observed toxicities $(n=3)$. Toxicity details are illustrated in Table 5. A very small number of patients had EPIC questionnaires available for interrogation following SBRT. Although difficult to generalize given the small patient numbers, bowel quality of life appears to decline 1 month following SBRT with gradual improvements seen at 3-4 months and 6-9 months (Table 3).

All patients who developed toxicity were treated to a total dose of $3500 \mathrm{cGy}$ in five fractions. The documented median rectal point dose maximum was 3853 cGy in patients who developed toxicity, which was slightly higher than that of the entire IBD cohort (3754 cGy). Interestingly, the two patients treated with pelvic nodal irradiation were not found to have toxicity. Those patients who underwent pre-treatment rectal spacer placement also did not develop toxicity. Of note, all patients who 
Table 3 EPIC questionnaire

\begin{tabular}{|c|c|c|c|c|}
\hline & $\begin{array}{l}\text { Baseline } \\
(n=14)\end{array}$ & $\begin{array}{l}1 \text { month } \\
(n=5)\end{array}$ & $\begin{array}{l}\text { 3-4 months } \\
(n=4)\end{array}$ & $\begin{array}{l}\text { 6-9 months } \\
(n=4)\end{array}$ \\
\hline \multicolumn{5}{|c|}{ HRQOL Bowel domain summary } \\
\hline Median & 90 & 71 & 64 & 82 \\
\hline Mean & 84 & 59 & 62 & 75 \\
\hline Range & $38-100$ & $7-95$ & $23-96$ & $41-96$ \\
\hline \multicolumn{5}{|c|}{ Domain-specific HRQOL subscales } \\
\hline \multicolumn{5}{|l|}{ Function } \\
\hline Median & 95 & 71 & 68 & 80 \\
\hline Mean & 87 & 59 & 63 & 77 \\
\hline Range & $46-100$ & $11-89$ & $21-96$ & $50-96$ \\
\hline \multicolumn{5}{|l|}{ Bother } \\
\hline Median & 91 & 71 & 61 & 84 \\
\hline Mean & 81 & 59 & 61 & 74 \\
\hline Range & $29-100$ & $4-100$ & $25-96$ & $32-96$ \\
\hline
\end{tabular}

developed toxicity were receiving IBD medical treatment prior to SBRT often with systemic medication.

\section{Discussion}

The pathophysiological mechanism of radiation-induced damage in IBD remains nebulous. It may be a multifactorial process involving underlying IBD sensitivities to vascular damage, inherently altered DNA repair pathways, and a susceptibility to excessive free radical damage [21$23]$. Conversely, radiation has well known immunomodulatory properties and can be notably cytotoxic to immune cells even in low doses yielding anti-inflammatory effects [24-26]. The immunosuppressive effect of radiation has been recently explored for the treatment of COVID19-related pneumonia with mixed results [27]. Thus, it is fair to ask whether radiation might suppress the dysregulated and hyperactive mucosal immune response in the rectum leading to improved symptomatology, which is intriguingly what was observed by a Gestaut et al. [16].

Gestaut et al. reported a group of 18 patients with exclusively prostate cancer treated with a variety of radiation modalities including three-dimensional conventional radiation therapy (3DCRT), intensity modulated radiation therapy (IMRT), and low dose rate brachytherapy (12 patients received EBRT). The majority of patients $(79 \%)$ required IBD medication prior to and during radiation treatment. Similar to our study, remarkably low GI toxicity was observed with no instances of grade 3 toxicity identified. Of note, grade 2 proctitis was observed more frequently following 3DCRT, prompting the authors to advocate for the use of more conformal radiation techniques (e.g. IMRT). The use of "specialized" radiation techniques to minimize late toxicity was also observed in the aforementioned MGH publication [12].
Interestingly, the overall cohort demonstrated decreased grade 1 diarrhea immediately following radiation, and the authors postulate this may be a result of radiation's effect in mitigating IBD symptoms, at least in the acute setting.

Excess GI toxicity risk in patients with IBD is difficult to compare to a non-IBD cohort due to limited patient numbers. However, Murphy et al. reviewed 16 patients with underlying IBD who were treated with EBRT for prostate cancer and attempted to identify case controls without IBD to delineate a comparative risk profile [17]. Interestingly, no difference in grade $2+$ toxicity was identified between patients with IBD and case controls. Late grade 2 toxicity was low at 10\% (vs. 17\% in Gestaut et al.), which could be explained by the lower numbers of patients who received concurrent IBD medication, (47\% versus $79 \%$ ) perhaps indicative of the lower severity of underlying IBD in the Murphy et al. patient cohort [16].

In a unique publication, Feagins et al. reviewed a cohort entirely of IBD patients who did or did not receive radiation for prostate cancer treatment-distinct from all other publications, which reviewed radiation patients who did or did not have IBD. Veterans Administration data was reviewed from 1996 to 2015 of patients treated for prostate cancer with a radiation versus a non-radiation modality [15]. Baseline characteristics between the radiation and non-radiation cohorts did not appear to be different. However, there was a twofold higher rate of IBD flares within the first year after radiation relative to those patients who did not receive radiotherapy as primary treatment. Nevertheless, there were no differences in high-grade toxicities (i.e. hospitalization or surgeries). The use of "IBD flare" as a metric for toxicity in this trial is unique-only Annede et al. published similarly. Whether IBD flares represent the equivalent of 


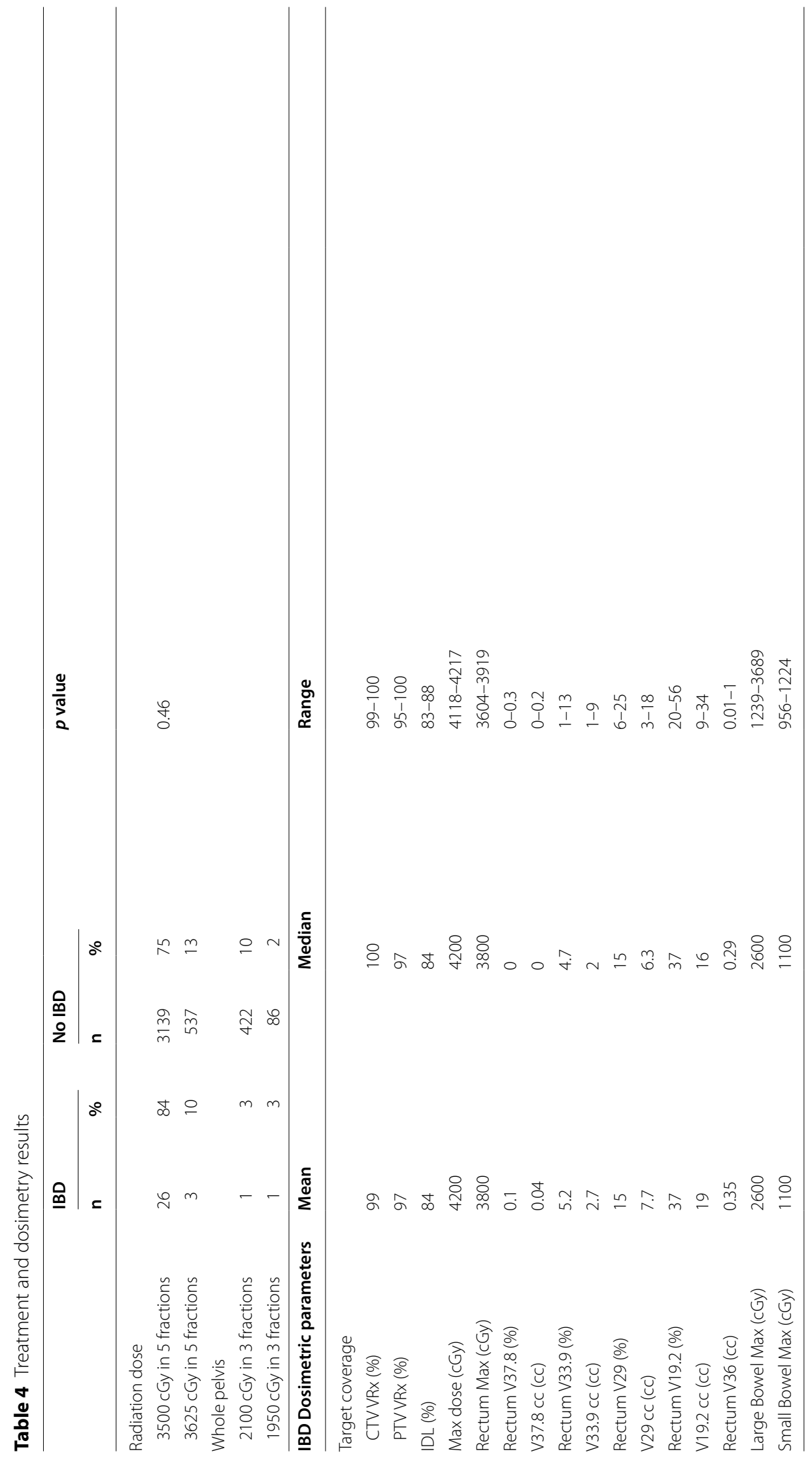


Table 5 Gastrointestinal toxicity (CTCAE version 5.0)

\begin{tabular}{|c|c|c|c|c|c|c|c|}
\hline Toxicity & $\begin{array}{l}\text { Time to } \\
\text { toxicity } \\
\text { (months) }\end{array}$ & IBD subtype & Risk group & Total dose (cGy) & IDL (\%) & $\begin{array}{l}\text { Rectal } \\
D_{\max }(c G y)\end{array}$ & Pre-SBRT IBD meds \\
\hline Grade 3 proctitis & $<1$ & UC & Int & 3500 & 84 & 3656 & Mesalamine \\
\hline Grade 2 proctitis & 29 & UC & Low & 3500 & 85 & 3852 & Prednisone \\
\hline Grade 2 proctitis & 22 & UC & $\operatorname{lnt}$ & 3500 & 83 & 3860 & Mesalamine \\
\hline Grade 2 hemorrhoids & 10 & $C D$ & High & 3500 & 86 & 3839 & Methotrexate \\
\hline Grade 1 rectal hemorrhage & $<1$ & $C D$ & High & 3500 & 86 & 3839 & Methotrexate \\
\hline Grade 1 hemorrhoids & 22 & UC & Int & 3500 & 83 & 3860 & Mesalamine \\
\hline
\end{tabular}

a low-grade CTCAE toxicity is difficult to establish, but highlights the importance of comparing apples to apples across publications with respect to toxicity metrics.

Attempts to exploit the inverse square law to minimize rectal toxicity using I-125 LDR brachytherapy was reported by Pai et al. [28]. A total of 13 patients with IBD received I-125 implants and a markedly elevated rate of grade $3+$ toxicity was observed at $23 \%$ and $15 \%$ for acute and late toxicity, respectively. Importantly, all patients who developed high-grade late toxicity underwent rectal biopsies shortly after brachytherapy implant. Similar high-grade toxicity was observed in patients with IBD treated with EBRT for colorectal cancer in the peri-operative setting [29]. These studies allude to an augmented toxicity risk with surgical manipulation of the pelvis in IBD cases following radiation, and highlight the importance of avoiding elective rectal interventions shortly after radiotherapy regardless of the presence of underlying bowel disease.

Literature for more heterogeneous groups of malignancies have highlighted several additional risk factors associated with toxicity including concurrent chemotherapy use and IBD location. Annede et al. reported a diverse group of patients with pelvic malignancies and IBD (12 of 28 with prostate cancer) treated with radiation from 1989 to 2015 [30]. External beam radiotherapy (primarily older 2D techniques) was delivered to a median dose of $53 \mathrm{~Gy}$. Of note, no patients had "active IBD" at baseline in this study. Only rectal IBD anatomical location was significantly correlated with IBD exacerbation within 6 months after radiation. With a median follow up of nearly 6 years, grade $3+$ GI toxicity rate was $11 \%$ and $4 \%$ for acute and late toxicity, respectively. Johns Hopkins Hospital reported on 24 patients with IBD who underwent primarily chemoradiation with conventional techniques for a heterogeneous group of malignancies (only one prostate cancer). High-grade toxicity $(3+)$ was reported at $21 \%$ and $8 \%$ for acute and late toxicity, respectively, with concurrent chemotherapy being the primary driver of toxicity.
Many of the aforementioned patients were treated with antiquated radiation techniques in an era when 3D planning did not exist and modern image guided radiation therapy (IGRT) had yet to be developed. Systemic review of the literature in this setting of a heterogeneous cancer cohort and EBRT treatment technique estimated the mean rate of acute and late grade $3+$ GI toxicity to be quite high at $20 \%$ (range: $11-27 \%$ ) and 15\% (range: 0-23\%), respectively [9]. Contemporary radiation incorporates detailed imaging including prostate MRI, exquisitely conformal radiation planning, and inter- and intra-fractional IGRT. Such improvements have led to decreases in radiation toxicity without a detriment in oncologic outcome in the non-IBD setting [31]. The most notable modern advancement from a rectal toxicity standpoint is the placement of a polyethylene glycolbased gel that creates an artificial space between the posterior aspect of the prostate and anterior aspect of the rectum. Placement of hydrogel spacers has consistently demonstrated superior dosimetry across nearly all dose volume parameters, and has translated into low rates of GI toxicity and excellent patient reported quality of life outcomes [32-37]. Advantages with the utilization of rectal spacers have been demonstrated not only in conventional radiotherapy treatments, but also in SBRT delivered with advanced MRI-guided radiotherapy. Alongi et al. report improvements not only in rectal dose sparing but also target volume coverage [38]. Furthermore, Cuccia et al. demonstrated rectal spacers seemed to "stabilize" the prostate by minimizing rotational antero-posterior shifts during MRI-guided radiotherapy delivery [39]. For patients with underlying IBD, such dramatic improvements in rectal dose and toxicity may be a panacea. In our particular IBD cohort, two patients underwent rectal spacer placement, and neither developed gastrointestinal toxicity.

Limitations of the present study include its retrospective nature, relatively short median follow up, and limited patient numbers, which is a consequence of the rarity of the clinical situation. Nevertheless, this is one of the largest 
cohorts ever reported of patients with IBD treated with modern radiation, the most detailed and homogenous from a radiation technique standpoint, and the only report detailing outcomes following SBRT. Caution is warranted and careful selection of patients appears to be crucial. If possible, treatment should be avoided during active IBD flares, particularly if localized to the rectum, and patients should be well managed medically prior to treatment. Strong consideration should be made for use of rectal spacers in effort to minimize rectal exposure to radiation. Conformal radiation with rigorous IGRT should be utilized and following radiation elective biopsies of the rectum should be avoided at all costs. Nevertheless, contrary to historical lore, prostate radiotherapy in patients with underlying IBD does not appear to be as toxic in the modern era.

\section{Conclusion}

Caution is warranted when delivering therapeutic radiation to patients with IBD; however, modern radiation techniques appear to have mitigated the risk of GI side effects. To date, this is one of the largest groups of patients with IBD treated with radiation for prostate cancer and the only review of patients treated with SBRT. Delivery of 5-fraction SBRT using a non-coplanar robotic platform with tight posterior margins result in low rates of gastrointestinal toxicity with no significant detriment on oncologic outcome.

\begin{abstract}
Abbreviations
IBD: Inflammatory bowel disease; CD: Crohn's disease; UC: Ulcerative colitis; MGH: Massachusetts General Hospital; SBRT: Stereotactic body radiation therapy; PSA: Prostate specific antigen; CT: Computed tomography; MRI: Magnetic resonance imaging; OAR: Organs at risk; CTV: Clinical target volume; PTV: Planning target volume; GI: Gastrointestinal; CTCAE: Common Terminology Criteria for Adverse Events; EPIC: The Expanded Prostate Cancer Index Composite; SPSS: Statistical Package for Social Sciences; ECOG: Eastern Cooperative Oncology Group; ADT: Androgen deprivation therapy; HRQOL: Health Related Quality of Life; cGy: Centigray; DNA: Deoxyribonucleic acid; 3DCRT: Three-dimensional conventional radiation therapy; IMRT: Intensity modulated radiation therapy; EBRT: External beam radiation therapy; LDR: Low dose rate; IGRT: Image guided radiation therapy.
\end{abstract}

\section{Acknowledgements}

Not applicable.

\section{Authors' contributions}

JWL, SB, CM, MR, AS, TC, MW, JEG, AE, AK, SC, and JH all contributed to study concept, design, and/or acquisition of data. JWL, SB, CM, AS, and JH completed the data collection. JWL, SB, CM, AS, MR, and JH contributed to the data analysis. JWL, SB, CM, MR, AS, TC, MW, JEG, AE, AK, SC, and JH was responsible for drafting the manuscript. All authors contributed to revising and giving final approval to the manuscript. All authors agree to be accountable for all aspects of the work including accuracy and integrity. All authors read and approved the final manuscript.

\section{Funding}

Accuray research grant.

\section{Availability of data and materials}

The datasets used and/or analyzed during the current study are available from the corresponding author on reasonable request.

\section{Declarations}

Ethics approval and consent to participate

This single institutional review of patients treated with SBRT for prostate cancer was approved by the local Institutional Review Board (Study \# 00001269).

\section{Consent for publication}

Not applicable.

\section{Competing interests}

JWL and SB are paid speakers for Accuray. The remaining authors have no competing interests.

\section{Author details}

${ }^{1}$ Department of Radiation Oncology, NYCyberKnife at Perlmutter Cancer Center - Manhattan, Perlmutter Cancer Center at New York University Langone Hospital - Long Island, 150 Amsterdam Ave, New York, NY 11501, USA. ${ }^{2}$ Department of Radiation Medicine, Lenox Hill Hospital - Northwell Health, New York, NY 10075, USA. ${ }^{3}$ Department of Surgery, New York University Long Island School of Medicine, Mineola, NY 11501, USA. ${ }^{4}$ Department of Radiation Oncology, New York University School of Medicine, New York, NY, USA. ${ }^{5}$ Department of Radiation Medicine, Medstar Georgetown University Hospital, Washington, DC 20007, USA. ${ }^{6}$ Department of Urology, New York University Long Island School of Medicine, Mineola, NY 11501, USA.

Received: 10 June 2021 Accepted: 24 June 2021

Published online: 09 July 2021

\section{References}

1. Abraham C, Cho JH. Inflammatory bowel disease. N Engl J Med. 2009;361(21):2066-78. https://doi.org/10.1056/NEJMra0804647.

2. Loftus EV, Sandborn WJ. Epidemiology of inflammatory bowel disease. Gastroenterol Clin North Am. 2002;31(1):1-20. https://doi.org/10.1016/ s0889-8553(01)00002-4

3. Cosnes J, Gower-Rousseau C, Seksik P, Cortot A. Epidemiology and natural history of inflammatory bowel diseases. Gastroenterology. 2011:140(6):1785-94. https://doi.org/10.1053/j.gastro.2011.01.055.

4. Bernstein CN, Blanchard JF, Kliewer E, Wajda A. Cancer risk in patients with inflammatory bowel disease: a population-based study. Cancer. 2001;91(4):854-62. https://doi.org/10.1002/1097-0142(20010215)91:4\% 3c854:.:aid-cncr1073\%3e3.0.co;2-z

5. Civitelli F, Casciani E, Maccioni F, et al. Use of imaging techniques in inflammatory bowel diseases that minimize radiation exposure. Curr Gastroenterol Rep. 2015;17(7):28. https://doi.org/10.1007/s11894-015-0448-y.

6. Englund H, Lidén KK, Lind T, Sundström T, Karling P. Radiation exposure in patients with inflammatory bowel disease and irritable bowel syndrome in the years 2001-2011. Scand J Gastroenterol. 2017;52(3):300-5. https:// doi.org/10.1080/00365521.2016.1252945.

7. Grand DJ, Harris A, Shapiro J, et al. Risk factors for radiation exposure in newly diagnosed IBD patients. Abdom Radiol N Y. 2016;41(7):1363-9. https://doi.org/10.1007/s00261-016-0650-x.

8. Zakeri N, Pollok RCG. Diagnostic imaging and radiation exposure in inflammatory bowel disease. World J Gastroenterol. 2016;22(7):2165-78. https://doi.org/10.3748/wjg.v22.i7.2165.

9. Tromp D, Christie DRH. Acute and late bowel toxicity in radiotherapy patients with inflammatory bowel disease: a systematic review. Clin Oncol R Coll Radiol G B. 2015;27(9):536-41. https://doi.org/10.1016/j.clon. 2015.05.001.

10. Schofield PF, Holden D, Carr ND. Bowel disease after radiotherapy. J R Soc Med. 1983;76(6):463-6.

11. Hoffman M, Kalter C, Roberts WS, Cavanagh D. Early cervical cancer coexistent with idiopathic inflammatory bowel disease. South Med J. 1989;82(7):905-6. https://doi.org/10.1097/00007611-198907000-00027.

12. Willett CG, Ooi CJ, Zietman $A L$, et al. Acute and late toxicity of patients with inflammatory bowel disease undergoing irradiation for abdominal and pelvic neoplasms. Int J Radiat Oncol Biol Phys. 2000;46(4):995-8. https://doi.org/10.1016/s0360-3016(99)00374-0. 
13. Busti AJ, Hooper JS, Amaya CJ, Kazi S. Effects of perioperative antiinflammatory and immunomodulating therapy on surgical wound healing. Pharmacotherapy. 2005;25(11):1566-91. https://doi.org/10.1592/phco. 2005.25.11.1566.

14. Song DY, Lawrie WT, Abrams RA, et al. Acute and late radiotherapy toxicity in patients with inflammatory bowel disease. Int J Radiat Oncol. 2001:51(2):455-9. https://doi.org/10.1016/S0360-3016(01)01629-7.

15. Feagins LA, Kim J, Chandrakumaran A, et al. Rates of adverse IBD-related outcomes for patients with IBD and concomitant prostate cancer treated with radiation therapy. Inflamm Bowel Dis. 2020;26(5):728-33. https://doi. org/10.1093/ibd/izz175.

16. Gestaut MM, Swanson GP. Long term clinical toxicity of radiation therapy in prostate cancer patients with Inflammatory Bowel Disease. Rep Pract Oncol Radiother J Gt Cancer Cent Poznan Pol Soc Radiat Oncol. 2017;22(1):77-82. https://doi.org/10.1016/j.rpor.2016.10.005.

17. Murphy $\mathrm{CT}$, Heller $\mathrm{S}$, Ruth $\mathrm{K}$, et al. Evaluating toxicity from definitive radiation therapy for prostate cancer in men with inflammatory bowel disease: Patient selection and dosimetric parameters with modern treatment techniques. Pract Radiat Oncol. 2015;5(3):e215-22. https://doi.org/10. 1016/j.prro.2014.09.004.

18. White EC, Murphy JD, Chang DT, Koong AC. Low toxicity in inflammatory bowel disease patients treated with abdominal and pelvic radiation therapy. Am J Clin Oncol. 2015;38(6):564-9. https://doi.org/10.1097/COC. 0000000000000010

19. Jmour $O$, Pellat $A$, Colson-Durand $L$, et al. [Radiation therapy in patients with inflammatory bowel disease. A review]. Bull Cancer (Paris). 2018;105(5):517-522. https://doi.org/10.1016/j.bulcan.2018.02.005

20. King CR, Freeman D, Kaplan I, et al. Stereotactic body radiotherapy for localized prostate cancer: pooled analysis from a multi-institutional consortium of prospective phase II trials. Radiother Oncol J Eur Soc Ther Radiol Oncol. 2013;109(2):217-21. https://doi.org/10.1016/j.radonc.2013. 08.030 .

21. Kk S, Fm P, C B, FI M, R P. Deficient DNA repair in chronic ulcerative colitis. Cancer Detect Prev. 1997;21(6):540-545.

22. Korzenik JR. IBD: a vascular disorder? The case for heparin therapy. Inflamm Bowel Dis. 1997;3(2):87-94.

23. Grisham MB. Oxidants and free radicals in inflammatory bowel disease. Lancet Lond Engl. 1994;344(8926):859-61. https://doi.org/10.1016/s01406736(94)92831-2.

24. Trott KR. Therapeutic effects of low radiation doses. Strahlenther Onkol Organ Dtsch Rontgengesellschaft Al. 1994;170(1):1-12.

25. Trott KR, Kamprad F. Radiobiological mechanisms of anti-inflammatory radiotherapy. Radiother Oncol J Eur Soc Ther Radiol Oncol. 1999;51(3):197-203. https://doi.org/10.1016/s0167-8140(99)00066-3.

26. Roedel F, Kley N, Beuscher HU, et al. Anti-inflammatory effect of low-dose $X$-irradiation and the involvement of a TGF-beta1-induced downregulation of leukocyte/endothelial cell adhesion. Int J Radiat Biol. 2002;78(8):711-9. https://doi.org/10.1080/09553000210137671.

27. Hess CB, Nasti TH, Dhere V, et al. Immunomodulatory Low-Dose WholeLung Radiation for Patients with COVID-19-Related Pneumonia. Int J Radiat Oncol Biol Phys. Published online December 16, 2020. https://doi. org/10.1016/j.jirobp.2020.12.011
28. Pai HH, Keyes M, Morris WJ, Christie J. Toxicity after (125)I prostate brachytherapy in patients with inflammatory bowel disease. Brachytherapy. 2013;12(2):126-33. https://doi.org/10.1016/j.brachy.2012.04.008.

29. Chang BW, Kumar AMS, Koyfman SA, Kalady M, Lavery I, Abdel-Wahab M. Radiation therapy in patients with inflammatory bowel disease and colorectal cancer: risks and benefits. Int J Colorectal Dis. 2015;30(3):403-8. https://doi.org/10.1007/s00384-014-2103-8.

30. Annede P, Seisen T, Klotz C, et al. Inflammatory bowel diseases activity in patients undergoing pelvic radiation therapy. J Gastrointest Oncol. 2017;8(1):173-9. https://doi.org/10.21037/jgo.2017.01.13.

31. Zelefsky MJ, Kollmeier M, Cox B, et al. Improved clinical outcomes with high-dose image guided radiotherapy compared with non-IGRT for the treatment of clinically localized prostate cancer. Int J Radiat Oncol Biol Phys. 2012;84(1):125-9. https://doi.org/10.1016/j.jirobp.2011.11.047.

32. Hedrick SG, Fagundes M, Robison B, et al. A comparison between hydrogel spacer and endorectal balloon: An analysis of intrafraction prostate motion during proton therapy. J Appl Clin Med Phys. 2017;18(2):106-12. https://doi.org/10.1002/acm2.12051.

33. Song DY, Herfarth KK, Uhl M, et al. A multi-institutional clinical trial of rectal dose reduction via injected polyethylene-glycol hydrogel during intensity modulated radiation therapy for prostate cancer: analysis of dosimetric outcomes. Int J Radiat Oncol Biol Phys. 2013;87(1):81-7. https://doi.org/10.1016/j.jirobp.2012.12.019.

34. Susil RC, McNutt TR, DeWeese TL, Song D. Effects of prostate-rectum separation on rectal dose from external beam radiotherapy. Int J Radiat Oncol Biol Phys. 2010;76(4):1251-8. https://doi.org/10.1016/j.ijrobp.2009. 07.1679 .

35. Chao M, Ho H, Chan Y, et al. Prospective analysis of hydrogel spacer for patients with prostate cancer undergoing radiotherapy. BJU Int. 2018;122(3):427-33. https://doi.org/10.1111/bju.14192.

36. Whalley D, Hruby G, Alfieri F, Kneebone A, Eade T. SpaceOAR hydrogel in dose-escalated prostate cancer radiotherapy: rectal dosimetry and late toxicity. Clin Oncol R Coll Radiol G B. 2016;28(10):e148-154. https://doi. org/10.1016/j.clon.2016.05.005.

37. Chao M, Lim Joon D, Khoo V, et al. The use of hydrogel spacer in men undergoing high-dose prostate cancer radiotherapy: results of a prospective phase 2 clinical trial. World J Urol. 2019;37(6):1111-6. https://doi.org/ 10.1007/s00345-018-2502-5.

38. Alongi F, Rigo M, Figlia V, et al. Rectal spacer hydrogel in 1.5T MR-guided and daily adapted SBRT for prostate cancer: dosimetric analysis and preliminary patient-reported outcomes. Br J Radiol. 2021;94(1117):20200848. https://doi.org/10.1259/bjr.20200848

39. Cuccia F, Mazzola R, Nicosia L, et al. Impact of hydrogel peri-rectal spacer insertion on prostate gland intra-fraction motion during 1.5T MR-guided stereotactic body radiotherapy. Radiat Oncol Lond Engl. 2020;15(1):178. https://doi.org/10.1186/s13014-020-01622-3

\section{Publisher's Note}

Springer Nature remains neutral with regard to jurisdictional claims in published maps and institutional affiliations.

Ready to submit your research? Choose BMC and benefit from

- fast, convenient online submission

- thorough peer review by experienced researchers in your field

- rapid publication on acceptance

- support for research data, including large and complex data types

- gold Open Access which fosters wider collaboration and increased citations

- maximum visibility for your research: over 100M website views per year

At BMC, research is always in progress.

Learn more biomedcentral.com/submissions 